\title{
Pharmacokinetics of Total and Unbound Paclitaxel After Administration of Paclitaxel Micellar or Nab- Paclitaxel: An Open, Randomized, Cross-Over, Explorative Study in Breast Cancer Patients
}

\author{
Olof Borgå · Elsa Lilienberg • Helena Bjermo • Fredrik Hansson • \\ Nina Heldring $\cdot$ Renata Dediu
}

Received: June 26, 2019 / Published online: August 20, 2019

(C) The Author(s) 2019

\section{ABSTRACT}

Introduction: Paclitaxel micellar is a novel formulation of paclitaxel in which retinoic acid derivates solubilize paclitaxel. The aim of the present study was to compare the unbound and total plasma pharmacokinetics of the new formulation with those of nanoparticle albuminbound (nab)-paclitaxel and to further assess its safety.

Methods: In this open, randomized, cross-over study, 28 female patients with breast cancer were given paclitaxel micellar and nab-paclitaxel as a 1-h intravenous infusion at a dose of $260 \mathrm{mg} / \mathrm{m}^{2}$. Plasma samples were collected during $10 \mathrm{~h}$, which were projected to cover at least $80 \%$ of the area to infinite time, $\mathrm{AUC}_{\text {inf }}$.

Enhanced Digital Features To view enhanced digital features for this article go to https://doi.org/10.6084/ m9.figshare.9263270.

\section{O. Borgå}

Borgå PK Consulting, Stockholm, Sweden

E. Lilienberg · H. Bjermo · N. Heldring ( $₫)$

Oasmia Pharmaceutical AB, Uppsala, Sweden

e-mail: nina.heldring@oasmia.com

F. Hansson

CTC Clinical Trial Consultants AB, Uppsala, Sweden

R. Dediu

Arensia Exploratory Medicine in Collaboration with Institutul de Pneumoftiziologie "Marius Nasta",

Bucharest, Romania
Unbound paclitaxel was measured in ultrafiltrate of plasma. Total paclitaxel in plasma was measured after protein precipitation with acetonitrile. Both assays used ultra-performance liquid chromatography (UPLC) followed by MS/ MS for drug quantification. The unbound fraction, $\mathrm{fu}$, was calculated as the ratio between the unbound and the total concentration.

Results: No difference in $\mathrm{fu}$ of paclitaxel between the two formulations was observed. Statistical comparison of $\mathrm{AUC}_{0-10 \mathrm{~h}}$ and $C_{\max }$ of unbound paclitaxel demonstrated that the two formulations met the criteria for bioequivalence. Regarding total paclitaxel levels, $C_{\max }$ but not $\mathrm{AUC}_{0-10 \mathrm{~h}}$ met the criteria. This study supports a safe administration of paclitaxel micellar.

Conclusion: The two formulations, paclitaxel micellar and nab-paclitaxel, behaved similarly following infusion. Probably, both formulations dissociate immediately in the blood, whereupon released paclitaxel rapidly distributes into tissue. Judged from the bioequivalence demonstrated for unbound paclitaxel, the two formulations are considered clinically equivalent.

Trial Registration: EudraCT no.: 2010-01983827.

Funding: Oasmia Pharmaceutical AB.

Keywords: Apealea; Bioequivalence; Cancer; Cross-over; Nab-paclitaxel; Paclitaxel micellar; Pharmacokinetics 


\section{INTRODUCTION}

Paclitaxel has a very low solubility in water, reported to be $<0.1-0.32 \mu \mathrm{g} / \mathrm{ml}[1,2]$, and several strategies have been adopted for its solubilisation in water. The first marketed paclitaxel formulation was based on the solubilizers Cremophor EL and ethanol to enable parenteral administration of paclitaxel [3]. However, Cremophor EL-containing formulations have been associated with severe adverse events, in particular with severe hypersensitivity reactions; therefore, premedication with corticosteroids and antihistamines (H1- and $\mathrm{H} 2$-antagonists) is recommended before treatment [4]. To avoid these events as well as the need for premedication, other innovative formulations such as Abraxane $^{\circledR}$ (nanoparticle albumin-bound paclitaxel, nab-paclitaxel) and Apealea/Paclical (paclitaxel micellar) have been developed.

Paclitaxel micellar is a formulation of paclitaxel in which paclitaxel is formulated with the surfactant XR17. At the time of this study the drug:surfactant ratio was $1: 1.5(\mathrm{w} / \mathrm{w})$ but has since then been optimized to $1: 1.33(\mathrm{w} / \mathrm{w})$. XR17 is a mixture of two iso-forms of $\mathrm{N}$-retinoyl-L-cysteic acid methyl ester sodium salt. Once reconstituted in an aqueous solution for infusion, drug and surfactant are present as micelles at sizes of $20-30 \mathrm{~nm}$ in a clear solution. When the formulation has been administered intravenously, the micelles seem to disintegrate rapidly in the blood, thereby releasing paclitaxel [5]. Paclitaxel micellar is given without premedication. In the phase I study with micellar paclitaxel [5], given as a 1-h infusion in doses ranging from 90 to $275 \mathrm{mg} / \mathrm{m}^{2}$, the following paclitaxel pharmacokinetic (PK) parameter values (mean \pm SD) were obtained in a total of 25 patients with recurrent malignant solid tumours: $\left(t^{1 / 2}\right)_{\alpha} \quad 0.55 \pm 0.32 \mathrm{~h}, \quad\left(t^{1} / 2\right)_{\beta}$ $8.83 \pm 4.10 \mathrm{~h}, \quad \mathrm{CL} \quad 13.4 \pm 4.8 \mathrm{l} / \mathrm{h} / \mathrm{m}^{2}, \quad V_{\mathrm{ss}}$ $63.3 \pm 26.9 \mathrm{l} / \mathrm{m}^{2}$ and $V_{\beta} 155 \pm 49 \mathrm{l} / \mathrm{m}^{2}$.

Nab-paclitaxel is an albumin-stabilized nanoparticle formulation that is tolerated without any premedication [6]. The freeze-dried paclitaxel nanoparticles (approximate size $130 \mathrm{~nm}$ ) are covered with human albumin in order to form a stable colloidal solution of the drug when reconstituted with $0.9 \%$ saline. In an European Medicines Agency (EMA) assessment report of the formulation, it was suggested that the association of paclitaxel particles and albumin is weak, permitting the two substances to freely dissociate from each other when the formulation reaches the bloodstream [6]. Studies of plasma protein binding of paclitaxel as such have shown that paclitaxel is bound equally to $\alpha_{1}$-acid glycoprotein and albumin, and it was also indicated that it binds to lipoproteins [7].

The primary aim of the present study was to perform an exploratory comparison of the pharmacokinetic (PK) plasma profiles of both total and unbound paclitaxel plasma concentrations following administration of paclitaxel micellar and nab-paclitaxel. The two formulations were compared using a cross-over design in patients with metastatic breast cancer with administration of the same dose of paclitaxel during equally long infusion times. Secondary objectives were to assess the safety of paclitaxel micellar and specifically to assess infusion site reactions during the infusion.

\section{METHODS}

\section{Patients and Study Design}

In the present open, randomized, cross-over study performed during March 2014-May 2015, 33 female patients diagnosed with metastatic breast cancer were enrolled at ARENSIA Exploratory Medicine-Phase I unit, "Marius Nasta" Institutul de Pneumoftiziologie in Bucharest, Romania (see Fig. 1). The protocol was approved by the Ministry of Health, National Agency of Medicines and Medical Devices in Romania (EudraCT no. 2010-01983827) and the National Ethics Committee for the Clinical Study of Medicines, Romania (ref no. $845 ; 1767)$. The study was conducted in accordance with the protocol, regulatory requirements, Good Clinical Practice and ethical principles of the Declaration of Helsinki. Informed consent was obtained from all individual participants included in the study. 


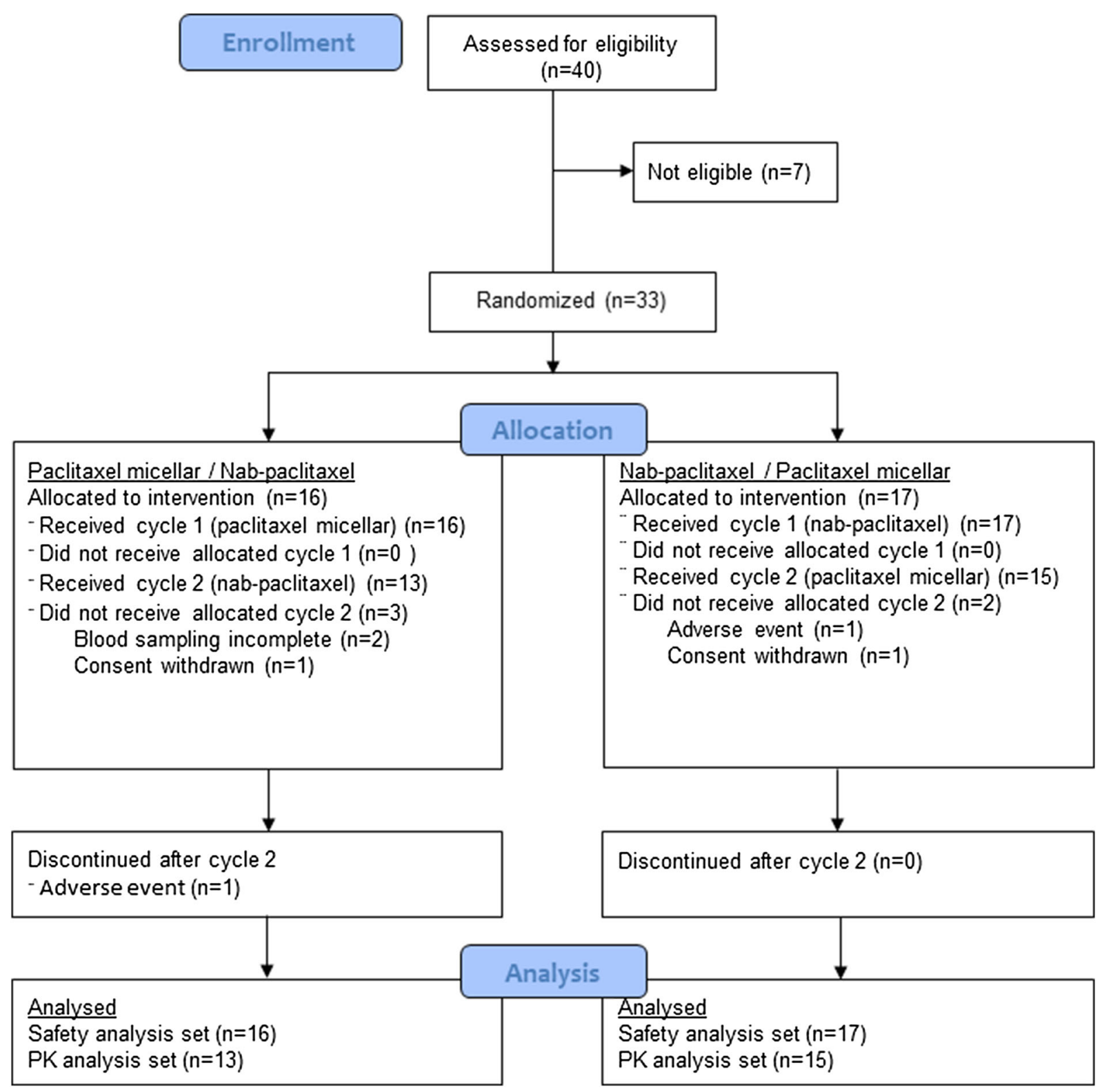

Fig. 1 Patient disposition. $N$ number of patients. The patients included in the PK analysis set were fewer than in the safety analysis set because bioanalysis data were not available for both cycles

\section{Patients}

Female patients $\geq 18$ years with a histologically or cytologically confirmed metastatic breast cancer, for whom previous treatment with anthracyclines had failed or anthracycline treatment was contraindicated, were included in the study. Other inclusion criteria were a life expectancy of at least 4 months and a willingness and ability to comply with the protocol during the study. Patients with impaired liver, renal and bone marrow functions, patients who had any uncontrolled medical problems that would preclude safe administration of the study drugs in the opinion of the investigator, patients who had had prior anticancer therapy or investigational agents within the last 30 days, and patients with a pre-existing peripheral neuropathy ( $\geq$ grade 2 ), pregnancy or body 
surface area $>2.0 \mathrm{~m}^{2}$ were excluded from the study.

\section{Study Design and Drug Preparation}

Sample size was calculated to 14 patients in each sequence (total sample size 28) to allow concluding the equivalence of the two formulations with $90 \%$ power assuming the mean square error (ln scale) for $\mathrm{AUC}_{0-10 \mathrm{~h}}$ to be 0.241 (the standard deviation differences: 0.341) and the expected ratio of means to be 1.000 [5]. If it was not possible to obtain complete PK sampling during both treatment cycles, the patient was replaced, and an additional patient was randomized.

The patients were randomized to two 21-day treatment cycles. A single dose of $260 \mathrm{mg} / \mathrm{m}^{2}$ paclitaxel was given at day 1 as a 1 -h intravenous infusion as either paclitaxel micellar or nab-paclitaxel in the first cycle and the other formulation in the second cycle. Blood sampling for PK evaluation was performed during both treatment cycles. Toxicity criteria were assessed according to National Cancer Institute's Common Terminology Criteria for Adverse Events (CTCAE), version 4.0. Infusion site reactions were assessed by visual inspection during the infusion and any symptoms or signs of pain, tenderness, erythaema and swelling were graded according to the Food and Drug Administration's (FDA) Toxicity Grading Scale for Healthy Adult and Adolescent Volunteers Enrolled in Preventive Vaccine Clinical Trials.

Before administration, each vial of lyophilized powder of paclitaxel micellar (Apealea ${ }^{\circledR} /$ Paclical $^{\circledR}$, Oasmia Pharmaceutical AB, Sweden) containing $60 \mathrm{mg}$ paclitaxel was dissolved in $60 \mathrm{ml}$ reconstitution solution (i.e., Ringer lactate or Ringer acetate for injection) resulting in a $1 \mathrm{mg} / \mathrm{ml}$ paclitaxel solution. The lyophilized powder of nab-paclitaxel (Abraxane ${ }^{\circledR}$, Celgene Europe Limited, UK) was reconstituted according to the product label [8] before administration.

\section{Paclitaxel Pharmacokinetics}

\section{Blood Sampling}

Blood samples of $15 \mathrm{ml}$ were collected during $10 \mathrm{~h}$ at each treatment cycle to enable comparisons of total and unbound plasma concentrations as well as the unbound fraction of paclitaxel during and after administration. This relatively short sampling interval was chosen since the majority of the total area under the curve to infinite time, $\mathrm{AUC}_{\mathrm{inf}}$, is generated during the first $10 \mathrm{~h}$, as the mean residual area (AUC 10 h-inf) accounts for only $15.7 \pm 8.6 \%$ of $\mathrm{AUC}_{\text {inf }}$ [5]. The EMA guideline on the investigation of bioequivalence requires that at least $80 \%$ of the AUC is covered by the sampling scheme [9].

Blood sampling was performed at the following time points: $0 \mathrm{~min}$ (pre-dose), $30 \mathrm{~min}$ (during infusion), $1 \mathrm{~h}$ (immediately prior to termination of infusion), $1.5 \mathrm{~h}, 3 \mathrm{~h}, 5 \mathrm{~h}$ and $10 \mathrm{~h}$ after the start of the 1-h infusion. The sampling was done in the arm on the opposite side relative to the site of the infusion. The blood samples were collected in $\mathrm{K}_{2}$ EDTA tubes followed by centrifugation. Thereafter, the plasma was transferred to and stored in cryovials at $-70^{\circ} \mathrm{C}$ and shipped on dry ice to the bioanalytical laboratory.

\section{Drug Analysis}

Total and unbound paclitaxel analyses were conducted using validated ultra-high-performance liquid chromatography with tandem mass spectrometry (UPLC-MS/MS) methods. The analyses and validations were performed at ICON Bioanalytical Laboratory Services, Inc. (NY, USA). The Waters Acquity liquid chromatography system used a Fortis C18 column $(1.7 \mu \mathrm{m}, 2.1 \times 100 \mathrm{~mm})$ with a gradient flow consisting of $0.2 \%$ formic acid in $10 \mathrm{mM}$ ammonium formate and $0.3 \%$ formic acid in acetonitrile at a $0.4 \mathrm{ml} / \mathrm{min}$ flow rate. 
Analysis of Total Paclitaxel Each 100- $\mu$ l aliquot of standard, QC, or study sample was mixed with $25 \mu \mathrm{l}$ of working internal standard solution $[2500 \mathrm{ng} / \mathrm{ml}$ in $50 / 50(\mathrm{v} / \mathrm{v})$ acetonitrile/water]. A 500- $\mu$ l aliquot of acetonitrile was added and the samples were thoroughly mixed and then centrifuged at $3750 \mathrm{rpm}$ for approximately $5 \mathrm{~min}$. A $300-\mu \mathrm{l}$ aliquot of the supernatant was diluted with $200 \mu$ l of mobile phase. Then, a 10- $\mu$ l aliquot was injected onto an LCMS/MS system for analysis. The method was validated over a range from $40 \mathrm{ng} / \mathrm{ml}$ (lower limit of quantification, LLOQ) to $4000 \mathrm{ng} / \mathrm{ml}$. The inter-run overall precision and accuracy for all QCs including LLOQ were $\leq 2.83 \%$ and -1.75 to $0.00 \%$, respectively. The intra-run overall precision and accuracy for all QCs including LLOQ were $\leq 3.20 \%$ and -3.40 to $2.50 \%$, respectively.

Analysis of Unbound Paclitaxel Each 500- $\mu$ l aliquot of standard, QC, or study sample was transferred to a Centrifree centrifugal filter and following a 30-min equilibration period the samples were filtered by centrifugation for 15 min. A $25-\mu l$ aliquot of each ultrafiltrate was transferred to the appropriate well of a 96-well plate. A $75-\mu l$ aliquot of internal standard (30 ng/ml paclitaxel-d5 in acetonitrile) and $50 \mu \mathrm{l}$ of mobile phase A were added to each well and the samples were mixed. A 20- $\mu$ l aliquot was injected onto an LC-MS/MS system for analysis. The method was validated over a range from $1.0 \mathrm{ng} / \mathrm{ml}$ (i.e., LLOQ) to $350 \mathrm{ng} / \mathrm{ml}$. Interrun overall precision and accuracy for all QCs including LLOQ were $\leq 4.60 \%$ and -6.25 to $-3.67 \%$, respectively. The intra-run overall precision and accuracy for all QCs including LLOQ were $\leq 3.77 \%$ and -10.5 to $-0.3 \%$, respectively.

\section{Pharmacokinetic Evaluation}

Non-compartmental analysis was performed with individual plasma concentration-time data from each patient using the WinNonlin pharmacokinetic software (Pharsight Corp., Mountain View, CA, USA). The following PK parameters were calculated from total and unbound plasma levels of paclitaxel: the maximum plasma concentration $\left(C_{\max }\right)$, time of occurrence of $C_{\max }\left(T_{\max }\right)$, area under the plasma concentration vs. time curve from 0 to $10 \mathrm{~h}\left(\mathrm{AUC}_{0-10 \mathrm{~h}}\right)$ and unbound fraction of drug in plasma (fu).

All AUC values for the unbound or total drug concentration $\left(C_{\mathrm{u}}\right.$ and $C_{\mathrm{tot}}$, respectively) were calculated using the linear trapezoidal method. The fu was calculated as $C_{\mathrm{u}} / C_{\text {tot }}$. The exact times rather than the nominal times for sampling were used in all calculations. Samples with plasma concentration below the LLOQ were treated as zero.

\section{Statistical Comparisons of the Two Formulations}

The two formulations were statistically compared by analysing $\mathrm{AUC}_{0-10 \mathrm{~h}}$ and $C_{\max }$ as well as their unbound counterparts, $\mathrm{AUC}_{0-10 \mathrm{~h}, \mathrm{u}}$ and $C_{\max _{\mathrm{u}}}$, using analysis of variance (ANOVA) according to classical principles to establish bioequivalence. Factors for sequence, patient within sequence, period and formulation were included in the model. The $\mathrm{AUC}_{0-10 h}$ of fu, i.e., the integral of the fu-time curve over the entire 10-h study interval, was analysed in the same way. Prior to analysis, data were transformed using a logarithmic transformation. The statistical method for testing relative bioavailability was based upon the $90 \%$ confidence interval for the ratio of the population means (test/reference) for the parameters under consideration. As in classical bioequivalence analysis, the acceptance range for the $\mathrm{AUC}_{0-10 \mathrm{~h}, \mathrm{u}}$ ratio, $C_{\text {max }_{\mathrm{u}}}$ ratio and $\mathrm{AUC}_{0-10 \mathrm{~h}}$ of the fu ratio was $0.80-1.25$ $[9,10]$. A possible sequence effect on the investigated parameters, i.e., whether parameters differed between the two study periods, was investigated. All statistical analyses were performed using SAS version 9.2 (SAS Institute, Cary, NC).

The data sets generated during and/or analysed during the current study are not publicly available because of confidentiality of Oasmia Pharmaceutical $A B$ but are available from the corresponding author upon reasonable request. 


\section{RESULTS}

\section{Patient Characteristics}

Patient disposition is presented in Fig. 1. A total of 33 patients were randomized, of which 31 received paclitaxel micellar and 30 received nab-paclitaxel. Five patients were treated with only one of the drugs; reasons for withdrawal were incomplete blood sampling $(n=2)$, withdrawal of consent $(n=2)$ and adverse event specified as disease progression $(n=1)$. The remaining 28 patients received both treatment cycles and were included in the PK analysis set. All randomized patients were included in the safety analysis set. All included patients $(n=33)$ were Caucasian females whereof 28 (85\%) were post-menopausal. The mean $\pm \mathrm{SD}$ of their age was $60.2 \pm 11.9$ years, height was $156.9 \pm 6.8 \mathrm{~cm}$, weight was $68.5 \pm 13.6 \mathrm{~kg}$ and body surface area was $1.7 \pm 0.2 \mathrm{~m}^{2}$.

\section{Paclitaxel Pharmacokinetics}

Plasma concentration data of both total and unbound paclitaxel were obtained in all patients included in the PK analysis set. The statistics of all studied PK parameters are summarized per formulation in Table 1.

\section{Total Concentrations of Paclitaxel}

With both formulations, the mean total plasma level of paclitaxel increased during the infusion to peak around $8000 \mathrm{ng} / \mathrm{ml}$ and then declined rapidly to one-tenth of this value during the following $2 \mathrm{~h}$ (Fig. 2). Thereafter, the decline became less and less steep. A distinct final monoexponential phase was not reached during the $10 \mathrm{~h}$ that plasma levels were monitored. The initial part of the plasma curves of total paclitaxel were similar for the two formulations and the mean total $C_{\max }$ after nab-paclitaxel, $8073 \pm 4124 \mathrm{ng} / \mathrm{ml}(n=28)$, was similar to the mean total $C_{\max }$ after paclitaxel micellar, $8006 \pm 1703 \mathrm{ng} / \mathrm{ml}(n=28)$.

The mean curves of paclitaxel micellar and nab-paclitaxel of all individuals were almost superimposable when plotted in linear-linear mode (Fig. 2a). In the log-linear plot (Fig. 2b),
Table 1 Summary statistics of PK parameters, all presented as mean $\pm S D$

\begin{tabular}{lcc}
\hline Parameter & \multicolumn{2}{c}{ Formulation $(\boldsymbol{n}$ number of patients $)$} \\
\cline { 2 - 3 } & $\begin{array}{l}\text { Paclitaxel micellar } \\
(\boldsymbol{n}=\mathbf{2 8})\end{array}$ & $\begin{array}{l}\text { Nab-paclitaxel } \\
(\boldsymbol{n}=\mathbf{2 8})\end{array}$ \\
\hline Total paclitaxel & & $11,388 \pm 3123$ \\
$\mathrm{AUC}_{0-10 \mathrm{~h}}$ & $13,484 \pm 3491$ & \\
$(\mathrm{~h} \mathrm{ng} / \mathrm{ml})$ & & $4073 \pm 4124$ \\
$C_{\max }(\mathrm{ng} / \mathrm{ml})$ & $8006 \pm 1703$ & \\
$T_{\max }(\mathrm{min})$ & $50 \pm 17$ & $580 \pm 172$ \\
$\mathrm{Unbound}_{\mathrm{n}} \mathrm{paclitaxel}$ & & \\
$\mathrm{AUC}$ & \\
$(\mathrm{h} \mathrm{ng} / \mathrm{ml})$ & $646 \pm 154$ & $416 \pm 229$ \\
$C_{\max }(\mathrm{ng} / \mathrm{ml})$ & $391 \pm 72$ & $50 \pm 20$ \\
$T_{\max }(\mathrm{min})$ & $48 \pm 18$ & \\
\hline
\end{tabular}

however, the mean curves tended to separate from each other after $1.5 \mathrm{~h}$, resulting in lower mean $\mathrm{AUC}_{0-10 \mathrm{~h}}$ of total paclitaxel after nab-paclitaxel $(11,388 \pm 3123 \mathrm{~h} \times \mathrm{ng} / \mathrm{ml})$ compared with after paclitaxel micellar $(13,484 \pm 3491 \mathrm{~h} \times \mathrm{ng} / \mathrm{ml})$.

\section{Unbound Concentrations of Paclitaxel}

The unbound plasma PK profile reflected the total PK profile, with concentrations of approximately $5 \%$ of the corresponding total concentrations. Thus, the unbound curves peaked at around $400 \mathrm{ng} / \mathrm{ml}$ (Fig. 3). Concentrations at the last collection time point, $10 \mathrm{~h}$, were in the $3-15 \mathrm{ng} / \mathrm{ml}$ range and were well measurable since LLOQ was $1.0 \mathrm{ng} / \mathrm{ml}$. The mean unbound $C_{\max }$ after nab-paclitaxel, $416 \pm 229 \mathrm{ng} / \mathrm{ml}$, was similar to the mean unbound $C_{\max }$ after paclitaxel micellar, $391 \pm 72 \mathrm{ng} / \mathrm{ml}$. Similarly to what was seen with the total paclitaxel curves, the mean unbound paclitaxel curves for the two formulations overlapped during the initial part of the curves (Fig. 3). After $1.5 \mathrm{~h}$ the curves tended to separate and resulted in a mean $\mathrm{AUC}_{0-10 \mathrm{~h}, \mathrm{u}}$ of $580 \pm 172 \mathrm{~h} \times \mathrm{ng} / \mathrm{ml}$ after nab-paclitaxel while 

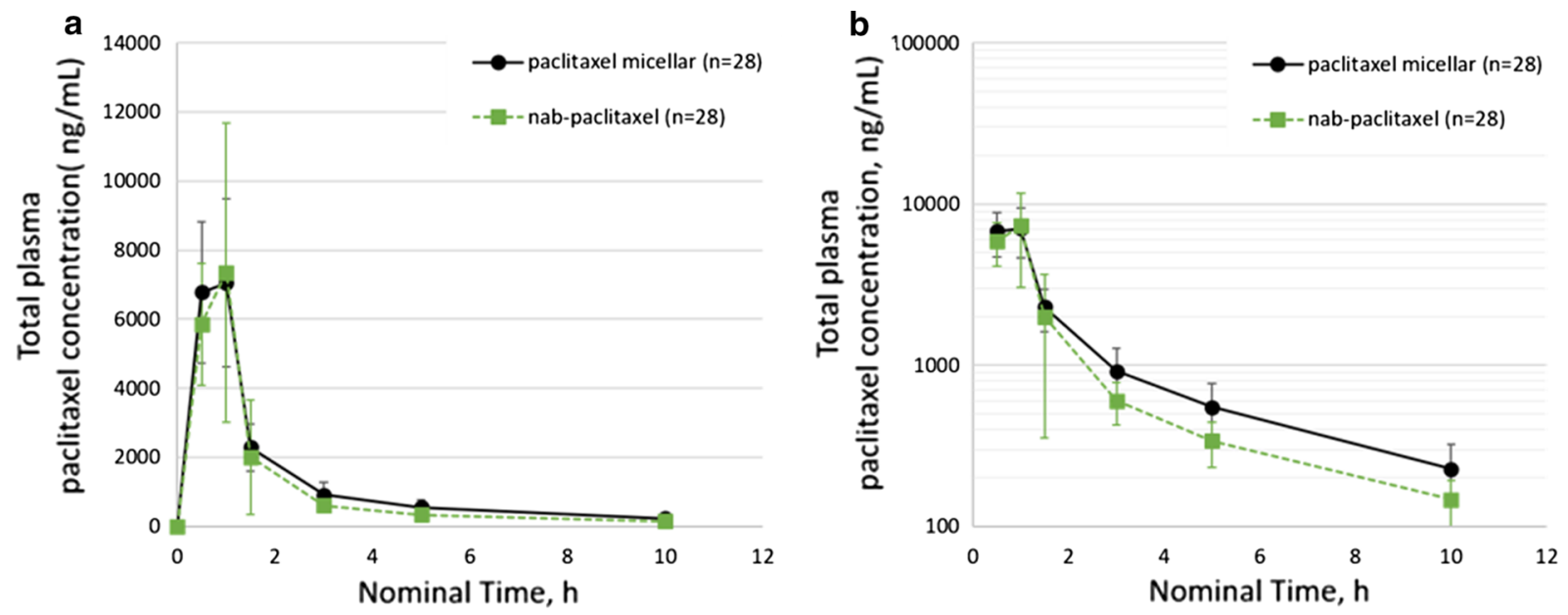

Fig. 2 Mean $( \pm S D)$ in all patients of total paclitaxel concentrations in plasma following a 1-h intravenous infusion of paclitaxel micellar or nab-paclitaxel, $260 \mathrm{mg} / \mathrm{m}^{2}$, plotted in a linear-linear and $\mathbf{b} \log$-linear scales
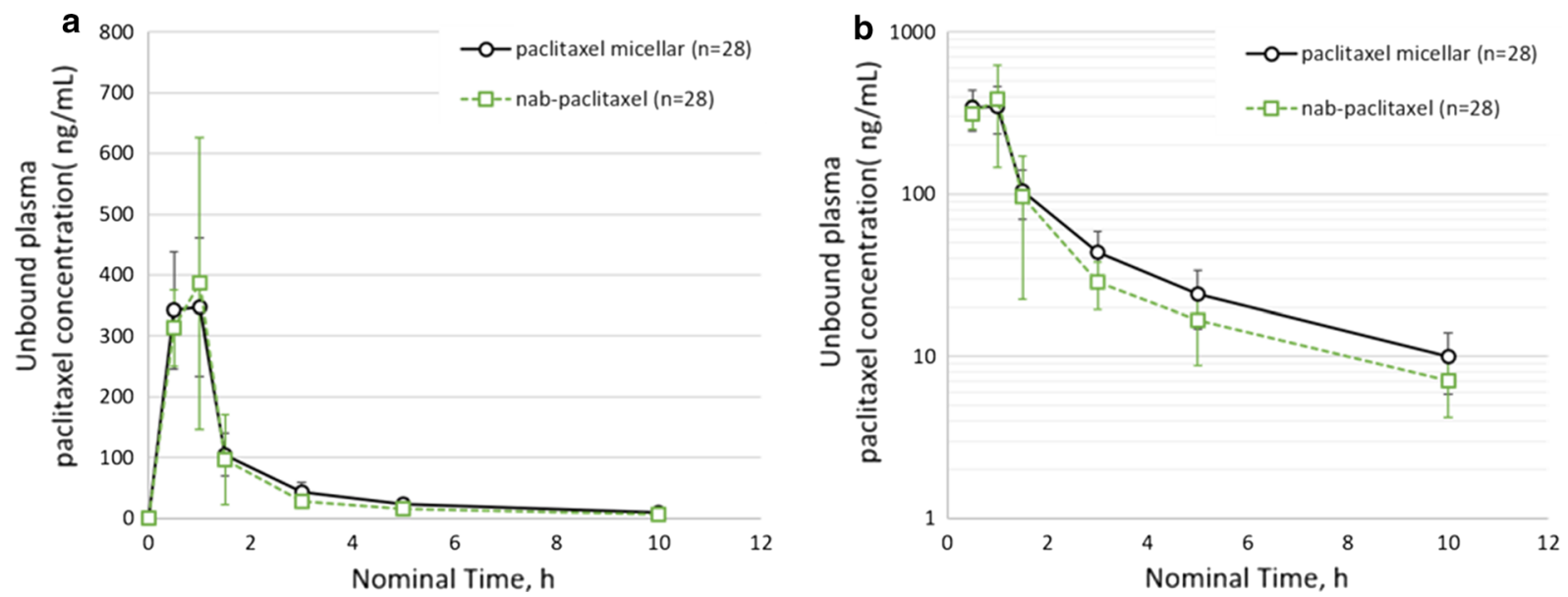

Fig. 3 Mean $( \pm S D)$ in all patients of unbound paclitaxel concentrations in plasma following a 1-h intravenous infusion of paclitaxel micellar or nab-paclitaxel, $260 \mathrm{mg} / \mathrm{m}^{2}$, plotted in a linear-linear and $\mathbf{b} \log$-linear scales

Table 2 Mean \pm SD of fu in all subjects, presented as \% unbound drug, at various times from start of the infusion for the two formulations

\begin{tabular}{lllllll}
\hline Formulation & \multicolumn{2}{l}{ Time $(\mathbf{h})(\boldsymbol{n}$ number of patients) } \\
\cline { 2 - 7 } & $\begin{array}{l}\mathbf{0 . 5} \\
(\boldsymbol{n}=\mathbf{2 7})\end{array}$ & $\begin{array}{l}\mathbf{1} \\
(\boldsymbol{n}=\mathbf{2 8})\end{array}$ & $\begin{array}{l}\mathbf{1 . 5} \\
(\boldsymbol{n}=\mathbf{2 8})\end{array}$ & $\begin{array}{l}\mathbf{3} \\
(\boldsymbol{n}=\mathbf{2 8})\end{array}$ & $\begin{array}{l}\mathbf{5} \\
(\boldsymbol{n}=\mathbf{2 8})\end{array}$ & $\begin{array}{l}\mathbf{1 0} \\
(\boldsymbol{n}=\mathbf{2 8})\end{array}$ \\
\hline Paclitaxel micellar & $5.2 \pm 0.9$ & $5.0 \pm 0.9$ & $4.5 \pm 0.6$ & $4.8 \pm 0.7$ & $4.4 \pm 0.6$ & $4.4 \pm 0.6$ \\
Nab-paclitaxel & $5.2 \pm 0.9$ & $5.3 \pm 0.7$ & $4.9 \pm 0.6$ & $4.8 \pm 0.6$ & $4.6 \pm 0.7$ & $4.8 \pm 1.5$ \\
\hline
\end{tabular}


it was $646 \pm 154 \mathrm{~h} \times \mathrm{ng} / \mathrm{ml}$ after paclitaxel micellar.

\section{Unbound Fraction}

The mean unbound fraction of paclitaxel in plasma, fu, was approximately $5.2 \%$ during the infusion of the two drugs when plasma levels were high (Table 2). At $3 \mathrm{~h}$ and after, a slightly lower fu was observed at about $4.4-4.8 \%$ with both formulations.

\section{Statistical Comparisons of the Two Formulations}

The two formulations were compared by testing of bioequivalence of AUC and $C_{\max }$ for both unbound and total paclitaxel and the analysis results are summarized in Table 3 . Bioequivalence was shown for unbound drug, since both $\mathrm{AUC}_{0-10 h, \mathrm{u}}$ and $C_{\text {max }_{u}}$ were within the acceptance range. Also, bioequivalence was shown for paclitaxel fu. Bioequivalence for total drug was not clearly demonstrated since the confidence interval for the nab-paclitaxel/paclitaxel micellar ratio for $\mathrm{AUC}_{0-10 \mathrm{~h}}(0.76-0.94)$ was slightly outside the confidence interval 0.80-1.25, while the ratio for $C_{\max }$ was within the confidence interval. No sequence effect on the investigated parameters was found.

\section{Tolerability and Side Effects}

All patients experienced at least one adverse event after the paclitaxel infusion, except for one patient after administration of paclitaxel micellar. No serious adverse events and no deaths or life-threatening events (CTCAE grade 4-5) were reported during the study. All reported adverse events are presented by treatment arm in Table 4 . The most frequent adverse events ( $>10$ events in total) were neutropenia (paclitaxel micellar: $n=19$, nab-paclitaxel: $n=17$ ), leukopenia (paclitaxel micellar: $n=15$, nab-paclitaxel: $n=14$ ), paraesthesia (paclitaxel micellar: $n=14$, nab-paclitaxel: $n=7$ ), pain (paclitaxel micellar: $n=9$, nab-paclitaxel: $n=9$ ) and nausea (paclitaxel micellar: $n=9$, nab-paclitaxel: $n=7$ ). The majority was of grade 1 or 2 but 21 grade-3 events were reported in 11 patients: 11 events after paclitaxel micellar infusion and 10 events after nab-paclitaxel infusion. These events were mainly connected

Table 3 Bioequivalence (BE) analyses of comparison of various PK parameters of total and unbound plasma concentrations of paclitaxel micellar with nab-paclitaxel

\begin{tabular}{|c|c|c|c|c|}
\hline \multirow[t]{2}{*}{ PK parameter } & \multicolumn{3}{|c|}{ Formulation log scale point estimate $(90 \% \mathrm{CI})$} & \multirow{2}{*}{$\begin{array}{l}\text { BE comparison } \\
\text { point estimate } \\
(90 \% \mathrm{CI})\end{array}$} \\
\hline & Nab-paclitaxel & $\begin{array}{l}\text { Paclitaxel } \\
\text { micellar }\end{array}$ & $\begin{array}{l}\text { Nab-paclitaxel/ } \\
\text { paclitaxel micellar }\end{array}$ & \\
\hline \multicolumn{5}{|l|}{ Total paclitaxel } \\
\hline $\begin{array}{r}\mathrm{AUC}_{0-10 \mathrm{~h}} \\
(\mathrm{~h} \mathrm{ng} / \mathrm{ml})\end{array}$ & $9.31(9.23: 9.39)$ & $9.48(9.39: 9.56)$ & $-0.17(-0.27:-0.07)$ & $0.85(0.76: 0.94)$ \\
\hline$C_{\max }(\mathrm{ng} / \mathrm{ml})$ & $8.91(8.80: 9.01)$ & $8.97(8.86: 9.07)$ & $-0.06(-0.20: 0.08)$ & $0.94(0.82: 1.09)^{\mathrm{BE}}$ \\
\hline \multicolumn{5}{|c|}{ Unbound paclitaxel } \\
\hline $\begin{array}{l}\mathrm{AUC}_{0-10 \mathrm{~h}, \mathrm{u}} \\
\left(\mathrm{h}^{*} \mathrm{ng} / \mathrm{ml}\right)\end{array}$ & $6.33(6.24: 6.41)$ & $6.44(6.36: 6.53)$ & $-0.12(-0.22:-0.01)$ & $0.89(0.80: 0.99)^{\mathrm{BE}}$ \\
\hline$C_{\max _{\mathrm{u}}}(\mathrm{ng} / \mathrm{ml})$ & $5.93(5.83: 6.04)$ & $5.95(5.85: 6.06)$ & $-0.02(-0.16: 0.12)$ & $0.98(0.86: 1.12)^{\mathrm{BE}}$ \\
\hline \multicolumn{5}{|l|}{ Ratio } \\
\hline $\mathrm{fu}^{\mathrm{a}}$ & $-0.75(-0.80:-0.71)$ & $-0.82(-0.86:-0.77)$ & $0.06(0.01: 0.12)$ & $1.07(1.01: 1.12)^{\mathrm{BE}}$ \\
\hline
\end{tabular}

$C I$ confidence interval, $B E$ indicates that bioequivalence is shown

a Test parameter $\mathrm{AUC}_{0-10 \mathrm{~h}}$ of the fu-time curve; unit hours 
Table 4 All reported adverse events by treatment arm

\begin{tabular}{|c|c|c|c|}
\hline System organ class & Preferred term & $\begin{array}{l}\text { Paclitaxel micellar } \\
(n=31)\end{array}$ & $\begin{array}{l}\text { Nab-paclitaxel } \\
(n=30)\end{array}$ \\
\hline \multirow[t]{4}{*}{ Blood and lymphatic system disorders } & Neutropenia & 19 & 17 \\
\hline & Leukopenia & 15 & 14 \\
\hline & Anaemia & 1 & 2 \\
\hline & Thrombocytopenia & 1 & 1 \\
\hline \multirow[t]{8}{*}{ Gastrointestinal disorders } & Nausea & 9 & 7 \\
\hline & Diarrhoea & 5 & 3 \\
\hline & Vomiting & 4 & 1 \\
\hline & Abdominal pain & 2 & 1 \\
\hline & Constipation & 2 & 1 \\
\hline & Mouth ulceration & 2 & 0 \\
\hline & Dyspepsia & 0 & 1 \\
\hline & Dysphagia & 1 & 0 \\
\hline \multirow[t]{6}{*}{ General disorders and administration site conditions } & Pain & 9 & 9 \\
\hline & Infusion site pain & 5 & 0 \\
\hline & $\begin{array}{l}\text { Injection site } \\
\text { inflammation }\end{array}$ & 4 & 0 \\
\hline & Disease progression & 0 & 2 \\
\hline & Fatigue & 1 & 1 \\
\hline & Oedema peripheral & 1 & 0 \\
\hline \multirow[t]{5}{*}{ Nervous system disorders } & Paraesthesia & 14 & 7 \\
\hline & Dizziness & 3 & 0 \\
\hline & Headache & 0 & 3 \\
\hline & Paraesthesia oral & 1 & 0 \\
\hline & Syncope & 0 & 1 \\
\hline \multirow[t]{6}{*}{ Skin and subcutaneous tissue disorders } & Alopecia & 4 & 4 \\
\hline & Pruritus & 4 & 1 \\
\hline & Erythaema & 1 & 0 \\
\hline & Pruritus generalised & 0 & 1 \\
\hline & Rash & 1 & 0 \\
\hline & Rash erythaematous & & 1 \\
\hline
\end{tabular}


Table 4 continued

\begin{tabular}{|c|c|c|c|}
\hline System organ class & Preferred term & $\begin{array}{l}\text { Paclitaxel micellar } \\
(n=31)\end{array}$ & $\begin{array}{l}\text { Nab-paclitaxel } \\
(n=30)\end{array}$ \\
\hline \multirow[t]{3}{*}{ Musculoskeletal and connective tissue disorders } & Arthralgia & 4 & 2 \\
\hline & Pain in extremity & 3 & 1 \\
\hline & Bone pain & 3 & 0 \\
\hline \multirow[t]{3}{*}{ Investigations } & $\begin{array}{l}\text { Alanine aminotransferase } \\
\text { increased }\end{array}$ & 2 & 2 \\
\hline & $\begin{array}{l}\text { Aspartate } \\
\text { aminotransferase } \\
\text { increased }\end{array}$ & 2 & 1 \\
\hline & $\begin{array}{l}\text { Gamma- } \\
\text { glutamyltransferase } \\
\text { increased }\end{array}$ & 1 & 1 \\
\hline \multirow[t]{2}{*}{ Vascular disorders } & Hypertension & 3 & 1 \\
\hline & Phlebitis & 1 & 0 \\
\hline Ear and labyrinth disorders & Vertigo & 2 & 0 \\
\hline \multirow[t]{2}{*}{ Infections and infestations } & Oral candidiasis & 1 & 0 \\
\hline & Tooth infection & 0 & 1 \\
\hline \multirow[t]{2}{*}{ Metabolism and nutrition disorders } & Decreased appetite & 1 & 0 \\
\hline & Hyperglycaemia & 0 & 1 \\
\hline Renal and urinary disorders & Dysuria & 2 & 0 \\
\hline Respiratory, thoracic and mediastinal disorders & Dysphonia & 1 & 1 \\
\hline Injury, poisoning and procedural complications & Skin injury & 0 & 1 \\
\hline $\begin{array}{l}\text { Neoplasms benign, malignant and unspecified } \\
\text { (including cysts and polyps) }\end{array}$ & Metastatic pain & 0 & 1 \\
\hline
\end{tabular}

to bone marrow depression (neutropenia and leukopenia) reported for six patients following paclitaxel micellar and three patients following nab-paclitaxel.

Infusion site reactions were only reported during infusion with paclitaxel micellar, where seven patients reported a total of ten infusion site reactions and the most frequent reaction was pain $(n=6)$.

\section{DISCUSSION}

The present study was undertaken to investigate and compare the PK plasma profiles of two intravenous formulations, paclitaxel micellar and nab-paclitaxel. The two formulations were shown to be bioequivalent regarding total $\left(C_{\max }\right)$ and unbound paclitaxel $\left(\mathrm{AUC}_{0-10 \mathrm{~h}, \mathrm{u}}\right.$ and $\left.C_{\max , \mathrm{u}}\right)$. Bioequivalence for the unbound drug is of particular importance since a basic principle 
of PK is that the unbound drug is the biologically active form exerting the pharmacological effect.

The tendency for mean curves of paclitaxel micellar and nab-paclitaxel to separate from each other after $1.5 \mathrm{~h}$ may possibly be an effect of metabolic interaction between paclitaxel and the surfactant XR17 occurring soon after administration of paclitaxel micellar, when plasma levels of the two compounds were high. However, further studies are needed to evaluate this possibility.

In general, the rate of bioavailability with intravenous formulations is controlled by the infusion rate, while the extent of bioavailability is by definition assumed to be complete. However, the formulation components in an intravenous formulation may affect the clearance, protein binding and distribution of the drug, whereof it follows that two different intravenous formulations might be non-equivalent. For example, in the case of intravenous formulations of paclitaxel, having Cremophor EL in the formulations has been shown to affect all three of the above-mentioned parameters $[11,12]$. There is evidence that this is caused by the paclitaxel released from the formulation being bound anew to the nanomedicine platform, i.e., Cremophor EL micelles, in a reversible manner. Increasing doses will lead to increasing plasma concentrations of Cremophor EL micelles, thus causing increased binding of paclitaxel in plasma, i.e., decreasing $\mathrm{fu}$. This is manifested as a more than proportional increase in total plasma levels of paclitaxel with increasing doses $[12,13]$. When it comes to nanomedicines, bioequivalence studies based on total plasma levels of the active drug may therefore not be sufficient, and they should be supplemented with measurements of unbound levels of the active drug [12].

When the nab-paclitaxel formulation is dispersed in saline, human albumin-covered particles of paclitaxel of approximately $130 \mathrm{~nm}$ diameter are formed [6]. However, the affinity of paclitaxel to albumin is weak and when reaching the blood stream the particles dissociate rapidly into their component molecules $[6,12]$. Based on this, the nab-paclitaxel formulation is basically just a vehicle for immediate delivery of the active pharmaceutical ingredient, paclitaxel, to the circulation. However, other authors have depicted a different scenario: that the nab-paclitaxel formulation dissociates in blood into smaller stable albumin-bound paclitaxel complexes [14-17]. These complexes are suggested to be able to utilize biologically important active transport processes to deliver paclitaxel to the tumour thanks to their albumin moiety [14-17]. Because of these conflicting views, the present study was designed to measure the unbound as well as total concentrations of paclitaxel and the ratio between the two, the unbound fraction, when comparing the PK of the two formulations. A rapid release of paclitaxel after drug administration of paclitaxel micellar has previously been established as its most plausible mode of drug delivery [5].

In the present data, fu was virtually identical for paclitaxel micellar and nab-paclitaxel during the entire sampling interval. As a matter of fact, by analysis of the area under the fu-time curve, fu was demonstrated to be bioequivalent for the two formulations. Furthermore, during the infusion part of the curves, the PK profiles of the two formulations were practically superimposable with regard to total and unbound drug thereby further emphasizing their similar rate of drug delivery. The notion of the formation of a stable albumin-paclitaxel complex specific for nab-paclitaxel is thus not supported by the present data. By another token, such a complex would not be able to pass through the ultrafiltration membrane. It would therefore manifest itself by an increased bound fraction of paclitaxel in plasma. Taken together, the present data indicate that both formulations dissociate immediately in the blood at similar rates, whereupon released paclitaxel rapidly distributes into tissue.

An expected decrease in the number of white blood cells was seen in both treatment arms, and the adverse events reported were in agreement with previously reported events for paclitaxel micellar [5]. Infusion site reactions of various kinds, predominately infusion site pain, have been observed in other clinical studies with paclitaxel micellar (unpublished results). This study also reports pain as the most 
common infusion site reaction. The severity grading indicates that either the pain did not interfere with activity or that a non-narcotic pain reliever could be used to avoid interference with daily activities. No serious events or deaths were reported in the present study, supporting paclitaxel micellar to be a safe therapy. However, the cross-over study design, the small number of patients and the fact that the patients received only one treatment with each compound prevent any definite conclusions regarding the safety profile of the two compounds.

\section{CONCLUSIONS}

This cross-over study of paclitaxel micellar and nab-paclitaxel demonstrated that the two formulations behaved similarly following intravenous administration. When reaching the blood, the formulations most likely release paclitaxel immediately. Judged from the bioequivalence demonstrated for unbound paclitaxel, the two formulations should be considered clinically equivalent.

\section{ACKNOWLEDGEMENTS}

The authors thank all participating patients and their families. We also thank the investigators and co-investigators involved in the clinical trial. In addition, the authors thank the ICON laboratory for the excellent bioanalysis.

Funding. This study was funded by Oasmia Pharmaceutical AB. This journal's Rapid Service Fee as well as the Open Access fee of this manuscript was funded by the study sponsor Oasmia Pharmaceutical AB. All authors had full access to all of the data in this study and take complete responsibility for the integrity of the data and accuracy of the data analysis.

Authorship. All named authors meet the International Committee of Medical Journal Editors (ICMJE) criteria for authorship for this article, take responsibility for the integrity of the work as a whole, and have given their approval for this version to be published.

Disclosures. Olof Borgå is a salaried consultant at Oasmia Pharmaceutical AB. Elsa Lilienberg is a full-time employee of Oasmia Pharmaceutical AB. Helena Bjermo is a full time employee of Oasmia Pharmaceutical AB. Fredrik Hansson was the statistician in the clinical trial. Nina Heldring is a full-time employee of Oasmia Pharmaceutical AB. Renata Dediu was the principal investigator of the clinical trial.

Compliance with Ethics Guidelines. All procedures performed in the study were in accordance with the ethical standards of the institutional and/or national research committee (Ministry of Health, National Ethics Committee for the Clinical Study of Medicines, Bucharest, Romania) and with the 1964 Helsinki Declaration and its later amendments or comparable ethical standards. Informed consent was obtained from all individual participants included in the study.

Data Availability. The data sets generated during and/or analysed during the current study are not publicly available because of the confidentiality of Oasmia Pharmaceutical AB but are available from the corresponding author upon reasonable request.

Open Access. This article is distributed under the terms of the Creative Commons Attribution-NonCommercial 4.0 International License (http://creativecommons.org/licenses/ by-nc/4.0/), which permits any noncommercial use, distribution, and reproduction in any medium, provided you give appropriate credit to the original author(s) and the source, provide a link to the Creative Commons license, and indicate if changes were made.

\section{REFERENCES}

1. Montaseri H, Jamali F, Rogers JA, Micetich RG. The effect of temperature, $\mathrm{pH}$, and different solubilizing agents on stability of taxol. Iran J Pharm Sci. 2004;1:43-51. 
2. Konno T, Watanabe J, Ishihara K. Enhanced solubility of paclitaxel using water-soluble and biocompatible 2-methacryloyloxyethyl phosphorylcholine polymers. J Biomed Mater Res Part A. 2003;65:209-14.

3. Safavy A. Recent developments in taxane drug delivery. Curr Drug Deliv. 2008;5:42-54.

4. FDA, US Label. Taxol ${ }^{\circledR}$ (paclitaxel) injection (patient information included), Reference ID: 2939751. Bristol-Myers-Squibb Company. 2011. https://www.accessdata.fda.gov/drugsatfda_docs/ label/2011/020262s049lbl.pdf. Accessed 02 May 2019.

5. Borgå $\mathrm{O}$, Henriksson $\mathrm{R}$, Bjermo $\mathrm{H}$, Lilienberg $\mathrm{E}$, Heldring N, Loman N. Maximum tolerated dose and pharmacokinetics of paclitaxel micellar in patients with recurrent malignant solid tumours: a dose-escalation study. Adv Ther. 2019;36:1150-63.

6. European Medicines Agency. Assessment report for Abraxane, EMEA/47053/2008. 2008. p. 1-45. https://www.ema.europa.eu/en/documents/assess ment-report/abraxane-epar-public-assessment-repo rt_en.pdf. Accessed 02 May 2019.

7. Kumar GN, Walle UK, Bhalla KN, Walle T. Binding of taxol to human plasma, albumin and alpha 1-acid glycoprotein. Res Commun Chem Pathol Pharmacol. 1993;80:337-44.

8. European Medicines Agency, EU label. Annex 1 SmPC Abraxane. Celgene Europe Ltd. 2018. p. 1-53. https://www.ema.europa.eu/en/documents/produ ct-information/abraxane-epar-product-information _en-0.pdf. Accessed 02 May 2019.

9. European Medicines Agency. Guideline on the investigation of bioequivalence. CPMP/EWP/QWP/ 1401/98 Rev 1/Corr**. 2010;1-27. https://www. ema.europa.eu/en/documents/scientific-guideline/ guideline-investigation-bioequivalence-rev1_en. pdf. Accessed 02 May 2019.
10. FDA, Guidance for industry. Statistical approaches to establishing bioequivalence. 2001. p. 1-48. https:// www.fda.gov/media/70958/download. Accessed 02 May 2019.

11. Gardner ER, Dahut WL, Scripture CD, et al. Randomized crossover pharmacokinetic study of solvent-based paclitaxel and nab-paclitaxel. Clin Cancer Res. 2008;14:4200-5.

12. Stern ST, Martinez MN, Stevens DM. When is it important to measure unbound drug in evaluating nanomedicine pharmacokinetics? Drug Metab Dispos. 2016;44:1934-9.

13. van Tellingen O, Huizing MT, Panday VR, Schellens JH, Nooijen WJ, Beijnen JH. Cremophor EL causes (pseudo-) non-linear pharmacokinetics of paclitaxel in patients. Br J Cancer. 1999;81:330-5.

14. Desai N, Trieu V, Yao Z, et al. Increased antitumor activity, intratumor paclitaxel concentrations, and endothelial cell transport of cremophor-free, albumin-bound paclitaxel, ABI-007, compared with cremophor-based paclitaxel. Clin Cancer Res. 2006;12:1317-24.

15. Chen N, Brachmann C, Liu X, et al. Albuminbound nanoparticle (nab) paclitaxel exhibits enhanced paclitaxel tissue distribution and tumor penetration. Cancer Chemother Pharmacol. 2015;76:699-712.

16. Lluch A, Álvarez I, Muñoz M, Angel Seguí M, Tusquets I, García-Estévez L. Treatment innovations for metastatic breast cancer: nanoparticle albuminbound (NAB) technology targeted to tumors. Crit Rev Oncol Hematol. 2013;89:62-72.

17. Fu Q, Sun J, Zhang W, Sui X, Yan Z, He Z. Nanoparticle albumin-bound (NAB) technology is a promising method for anti-cancer drug delivery. Recent Pat Anticancer Drug Discov. 2009;4:262-72. 